\section{Throwing out the baby with the bathwater?}

\author{
In den letzten Jahren ist Integrierte Produktpolitik Teil einer hitzigen Debatte \\ geworden. In ihrer letzten Kommunikation zum Thema hat die EU-Kommission \\ ihre Position und zukünftige Maßnahmen zusammengefasst. Bedauerlicherweise \\ sind die gewählten Formulierungen aber für den Leser unklar und eine Reihe \\ zentraler Maßnahmen fehlen.
}

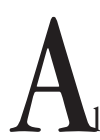

Von Chris van Rossem, Beatrice Kogg und Oksana Mont launched the official debate on Integrated Product Policy (IPP) as early as 1998, attempts to date to develop a formal EU IPP policy framework have not yet materialised. On June 18, 2003, the Commission adopted its Communication titled „IPP, Building on Environmental Life Cycle Thinking", the much anticipated follow-up to the Green Paper on IPP. In the Communication the Commission attempts to explain what IPP is and outlines an EU strategy for IPP. Generally speaking, many of the recommended measures first introduced in the Green Paper have been either removed completely or substantially slimmed down in the current Communication, to the disappointment of many actors. Interestingly, however, is the response from both the European Council of Ministers and the Parliament, which have recently adopted opinions that call for substantial changes to strengthen the formulation of IPP.

At this point in time the EU IPP is in a precarious phase: the Commission is continuing its work according to what was outlined in the Communication, but there is still no agreement on what role IPP shall ultimately have in the EU policy framework and there are no clear indications for when we can expect political decisions regarding its future development.

\section{IPP in EU Policy}

Given that the Commission acknowledges that IPP will contribute to meeting the goals of the 6th Environment Action Programme, it is not surprising that there are no quantifiable targets stated within the overarching objective of IPP. Unfortunately, this positioning of IPP is not clearly articulated in the Communication, which perhaps leads to unnecessary criticism with respect to quantifiable targets

for the policy.

Similarly, IPP is positioned to contribute towards the implementation of EU Sustainable Development Strategy and constitutes a major input to the tenyear framework of programmes on sustainable production and consumption. Figure 1 graphically illustrates the positioning of IPP in this respect. Although IPP is recognised as an important component to achieve the objectives of these overarching from IPP is not specified. More importantly, since IPP strongly advocates a process of first identifying and then optimising actions to reduce life cycle impacts of products, it is expected that this would involve various other environmental policy areas such as waste, chemical and energy, for example. However, very little attention is paid to clarifying the position of IPP with respect to these areas.

One of the key critiques against the current IPP Communication is that it is rather vague. COM (2003) 302 begins by presenting the rationale for a product-oriented approach to policy making. This is followed by a description of the IPP Approach, based on five guiding principles, which essentially form the 'ideology' behind the policy. programmes, the relative contribution expected

Although found relatively deep in the document, the stated primary aim of IPP is ,to reduce the environmental impacts from products throughout their life cycle, harnessing, where possible, a market driven approach“.

In terms of implementation, the EU IPP strategy is divided into two streams of action. The first, „Es tablishing the Framework Conditions for Continuous Improvements ", could be better described as a description of the policy tools that the Commission sees relevant within IPP. The second stream „Developing a Focus on Specific Products" outlines the envisioned pilot projects and the process to develop a methodology to target specific product groups, with which to apply the IPP approach at the EU level.

For each of the policy instruments listed in the first action stream of the strategy, the Commission also outlines the specific actions it intends to pursue in order to develop and expand the ,toolbox“. These actions are primarily information or research related, and in many instances they are also rather vaguely described. The specific actions under the

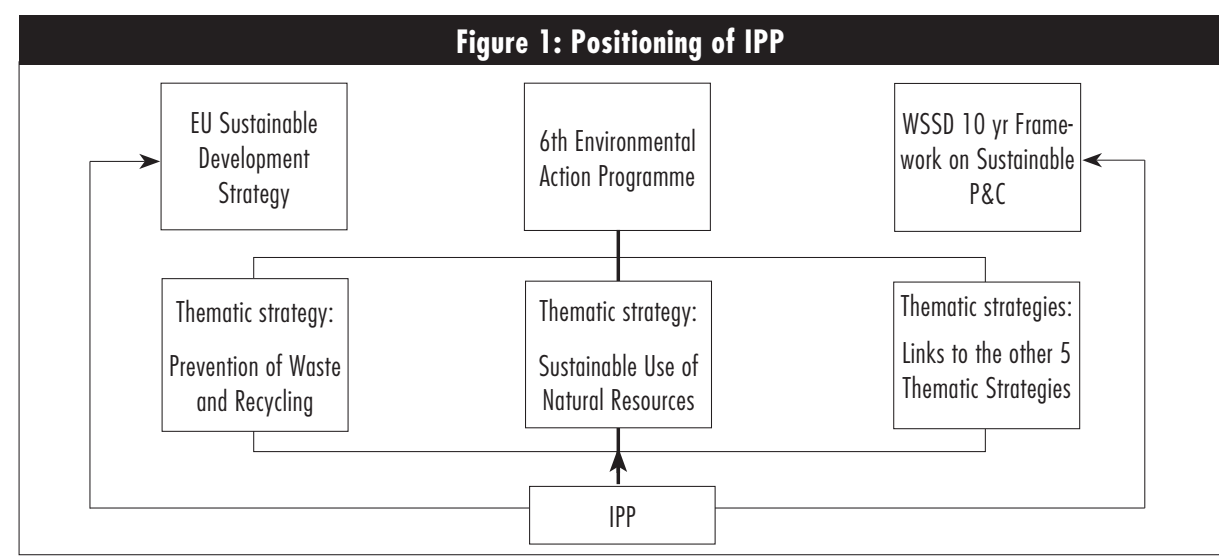

Source: IIIEE

second stream of activity in the strategy are more explicit and clear, however the process of identifying priority product groups is scheduled to last up to 3 to 4 years. The following table provides an overview of the main action items found in the Communication and categorises them by date.

\section{Key problem issues}

A thorough reading of the latest Communication on IPP is likely to leave the reader confused. It is, for example, not surprising that company representatives get puzzled when asked to integrate IPP thinking in the R\&D plans, when IPP is defined as being based on principles such as: working with the market, stakeholder involvement, and a variety of policy instruments. 


\begin{tabular}{|l|l|}
\hline \multicolumn{1}{|c|}{ Table I: Main action items of IPP Communication } \\
\hline 2003 & - Completed survey to determine the extent of greener public procurement \\
& - Communication on EU Standardisation and Environnemental Protection \\
& - Guideline on how to incorporate product perspective in EMAS by end 2004 \\
& - Decide whether to obtain EMAS II registration \\
- Start of Pilot Projects \\
- Start of Process of Identifying Target Products \\
- Handbook on best LCA practise by mid 2005 \\
- Discussion document on ways to promote the IPP approach in companies, including if general \\
obligations for specific products. New Approach Directives - EuP Framework \\
- Member States to develop action plans for greening public procurement (before 2006) \\
- Decision on Community action on EPD development \\
- End of Pilot Project \\
- Draw up an action programme by end of 2006, that is in line with the action plans to be \\
- developed by Member States that includes: \\
- Practical Handbook for public authorities \\
- Product Group database: web-based information on existing product criteria Prototype by 2003 \\
- Public Procurement website \\
- Member States report on Implementing IPP end of 2006 \\
- End of Identifying Target Products, maybe 2006 \\
- Start to address Target Products \\
- Report on Progress being made to implement IPP
\end{tabular}

There are however far more essential issues to address. In our opinion there are two fundamental drawbacks with the presented strategy. Firstly, the Communication fails to clarify what IPP is, or should be. Secondly, there is lack of concrete suggestions for political action. The Communication presents the ideology behind addressing productrelated environmental impacts, but does not provide a strategy for political action.

A fundamental problem with the current IPP Communication is the lack of clarity with regards to the roles and responsibilities of different actors in relation to IPP. First of all it is important that the role of the Commission itself in the IPP work is clearly defined. Secondly, the roles of decision makers at the EU and member state level also should be clearly defined. It is apparent that the Commission expects Member States to be a driving force for IPP; however no guidance for how the Member States should act is provided (other than a list of potential indicative roles).

Furthermore, the role of industry and other stakeholders in relation to IPP is still unclear. In the language of the current Communication, industry is encouraged to do their part in implementing IPP. We argue that it must be made clear that IPP is a tool for policymakers. While industry may provide important input into the process of making policy, they are, along with consumers and other actors, essentially the targets of these poli-
Source: IIIEE

med approach towards improving structured participation of stakeholders towards the goal of greening products and services. What must be cautioned, however, is any strategy that systematically tries to relieve the legislator in the environmental policy field. This is not to say that IPP will do this, but nonetheless the preference for voluntary enabling measures over more motivating measures must be recognised as potentially dangerous. When calling for more ,shared responsibility" to achieve environmental goals, governments must ensure that their capacity for developing direct regulation is maintained. This capacity is not only necessary for responding to environmental threats in a timely manner, but in the case when more flexible and decentralised measures fail to produce the desired effects.

One of the most important tasks of IPP is the integration of existing product-related policies and tools. This is recognized in the Communication, where there are also numerous other levels of integration put forth represented as: the integration of the life-cycle approach into policymaking, integration between environmental, social and economic policy objectives, integration of product and environmental policies, and integration or co-ordination of stakeholder involvement in the product chain. It is therefore surprising, and disappointing, that the IPP Communication does not provide any indication on how the various concepts of integration are to be achieved, including how the IPP ideology will be integrated into other EU policy areas, or how other policy areas will affect IPP. The Communication fails to clearly define what tasks the EU IPP strategy should solve on its own, and to distinguish these from the tasks that are expected to be solved by related policy initiatives. This is worrying, because while the Communication at length is listing different policy tools expected to contribute to the greening of products, it fails to explain how the EU IPP strategy will contribute to ensuring that these tools are implemented.

\section{vs. Naturschutz}

ist das Thema des Informationsdienstes

\section{Ökologisches Wirtschaften $5 / 04$}

Wenn Sie potenzielle Beiträge haben, wenden Sie sich bitte an die Redaktion.

\section{Communication without direction}

In the introduction parts of the Communication IPP is presented as umbrella policy that should provide a more systematic perspective on product-oriented policies and tools. However, while the strategy presents a toolbox containing numerous product-oriented policies and tools, it does not provide any directions for how to establish a framework for continuous improvement that applies horizontally to all product groups. No distinction is provided 
between tools that solve imminent problems and produce quick results and tools that lay the foundation for fundamental societal changes in the long term. The EU IPP strategy, as presented in the Communication, is alarmingly short sighted. Besides, there is also an overtone on enabling voluntary actions, with too little attention to motivating measures. Judging from the toolbox, it is not clear whether the IPP aims at laggards or forerunners and for which products or sectors the provided list of tools is appropriate.

In general it is surprising how little emphasis is placed on IPP as a trigger and support policy for environmentally sound innovations. This is especially apparent, given the emphasis and preference placed on voluntary initiatives within IPP. Although, there are implicit connections to the 5th and 6th Community Research Framework Programmes, specific actions on incorporating their results into IPP are missing. As both incremental and drastic changes of production and consumption patterns are required to reduce environmental impacts, the role of the IPP or its intentions in relation to innovation should be clearly stated.

We believe that education is not allocated proper attention in the Communication. If actors are to make decisions based on life cycle considerations, they need to be informed and educated about the life cycle logic. In addition to research, IPP must include comprehensive short- and longterm plans for educational activities directed at policy makers, current and future professionals, as well as current and future consumers. The Communication does not provide any guidance for developing measures on educating citizens and other stakeholders about the importance of life cycle thinking; but envisages Member States to have the primary responsibilities for education.

It also neglects the issue of consumption levels and excludes such innovative ideas as functional thinking and product-service systems. Eco-labelling is the only instrument mentioned in the IPP Communication that aims at reducing environmental impacts associated with the use phase. This is clearly insufficient. Measures are needed that will motivate and enable individuals and organisations to reflect upon consumption patterns and levels and incorporate lifecycle concerns in their decisions

\section{IPP and Services}

Finally, the EU Communication on IPP excludes services. There are however three compelling arguments to why services should be included.
First, it is not possible to delineate products from services because each product delivers certain services to consumers and services are used to deliver products. Thus there is always an intrinsic link between products and services and therefore, product-service packages are sold. Second, the service sector is a very large and important sector, with considerable associated environmental impacts, particularly in the southern parts of Europe where tourism is an important source of income. Third, since many environmental impacts are associated with services, considering merely environmental impacts of products may lead to transfer of environmental problems from products to services. Therefore system thinking is needed that is propagated by the concept of product-service-systems.

\section{- Putting IPP back on track}

Although there are compelling arguments for why national governments, and supranational structures such as the EU, must develop policy directed at significantly reducing the environmental impacts associated with production and consumption of products, the question still remains if we need IPP. This is a question that cannot be answered until we are able to clearly define the role that IPP should play. What should be its parts, how should they be implemented and most importantly, what type of results should IPP deliver? Looking at the documentation and the debate surrounding IPP, it is apparent that there is no real consensus on what IPP should be and thus there are several different plausible scenarios, for example:

(i) IPP as a tool for integration of different product policy initiatives.

(ii) IPP as a policy platform for promoting green product design.

(iii) IPP as a platform for voluntary measures in the product field.

(iv) IPP as a holistic environmental product policy approach.

All of these alternatives could constitute a useful contribution to the environmental policy mix, but it is imperative that a decision is made. We need to clarify the role of IPP in order to be able to communicate IPP without creating confusion so that political decisions can be made regarding the its future. Furthermore, we need this clarification to distinguish the problem areas that IPP will not address so that other, complementary policies can be developed where considered necessary. If we want to achieve the fundamental changes in current patterns of production and consumption that are widely perceived as necessary for achieving sustainable development, then we argue policy makers will need to address a range of tasks including:

Identification: Identification of high priority products and the policy tools that can promote improvements related to these products, as well as identification of general pathways to more sustainable production and consumption patterns, and the policy tools that will put us on identified paths.

Integration: Integration of lifecycle thinking into all relevant policy making as well as integration of different policies related to one product.

Motivation: The implementation of policy tools that will motivate relevant actors to integrate lifecycle oriented sustainability concerns into all relevant decisions, such as for example purchasing and design decisions.

Support: The implementation of enabling measures, such as e.g. education and the development of tools that for integrating lifecycle concerns into relevant situations.

Keeping track: Monitoring progress at European level, as well as on member state level.

It is not necessary or perhaps even desirable that IPP should solve all of these tasks. Indeed tasks, such as identification of general pathways to sustainable production and consumption, and the policy tools that can put us on this path, are perhaps more appropriate to address within the superseding policy frameworks, such as the Environmental Action Programme. Nevertheless, IPP certainly represents an opportunity for solving some of these tasks. In order to do that, however, we do not only need to come to a consensus regarding the role of IPP, but the proponents of IPP will need a considerable dose of political pragmatism so that ,the baby is not thrown out with the bathwater" when it comes to deciding about the future of IPP.

\section{Die Autorlnnen}

Chris van Rossem, Beatrice Kogg und Oksana Mont sind Doktoranden am International Institute for Industrial Environmental Economics (IIIEE) an der Univertsität Lund.

Kontakt: IIIEE, P.O. Box 196, SE-221 00 Lund. Tel. 0046-46 2220231, E-Mail: christopher.vanrossem@iiiiee.lu.se, beatrice.kogg@iiiee.lu.se, oksana.mont@iiiiee.lu.se 
(c) 20I0 Authors; licensee IÖW and oekom verlag. This is an article distributed under the terms of the Creative Commons Attribution Non-Commercial No Derivates License (http://creativecommons.org/licenses/by-nc-nd/3.o/), which permits unrestricted use, distribution, and reproduction in any medium, provided the original work is properly cited. 